\title{
II. Biological effects of radiation
}

Chairman: Dr. J. T. ScotT

\section{Chromosomal damage in human lymphocytes from radio-isotope therapy}

\author{
A. C. STEVENSON \\ M.R.C. Population Genetics Unit, Oxford
}

Much interest has been shown in recent years in the use of chromosomal damage in human circulating lymphocytes as an indicator of absorbed dose of external ionizing irradiation (Evans, 1967; Bender and Brewen, 1969; Dolphin, 1969; Scott, Sharpe, Batchelor, Evans, and Papworth, 1970). Because of the long mean life of such lymphocytes, induced damage is detectable many years after exposure, making it possible to assess dosage retrospectively, where reconstruction of damage in radiation accidents by physical methods has been difficult or impossible (Purrott, Lloyd, Dolphin, Eltham, Platt, Tipper, and Strange, 1973).

However, surprisingly little has been reported on the effects of therapeutic administration of radioisotopes. Indeed, before the study of patients who had had intra-articular injections of ${ }^{198} \mathrm{Au}$, there appear to have been only two papers on patients with polycythaemia vera treated by phosphorus 32 $\left({ }^{32} \mathrm{P}\right)$, and half a dozen reports on patients treated by iodine $131\left({ }^{131} I\right)$ for the control of hyperthyroidism or by ablation doses in the therapy of thyroid cancer.

None of these papers satisfy certain criteria, including numbers of patients, and numbers of cells examined, which are essential for examination of dose-damage relationship, and in most, including understandably the earlier studies, the techniques used and the methods of scoring and presentation of data, do not meet the requirements suggested in UNSCEAR (1969).
The present paper considers five sets of data accumulated in the MRC Population Genetics Unit in Oxford since 1971. Those relating to patients treated by intra-articular injections of ${ }^{198} \mathrm{Au}$ or ${ }^{90} \mathrm{Y}$, which have already been published (Stevenson, Bedford, Hill, and Hill, 1971b; Stevenson, Bedford, and 11 others, 1973), and unpublished data from a further series of ten patients of Dr. F. M. Andrews of Reading who had intra-articular injections of ${ }^{90} \mathrm{Y}$, twelve patients treated by Prof. J. B. Kinmonth and his colleagues in St. Thomas' Hospital by endolymphatic injections of ${ }^{32} \mathrm{P}$ labelled lipiodol, and 28 patients treated by Dr. G. Wiernik and his colleagues in the Churchill Hospital, Oxford, with ${ }^{131}$ I for hyperthyroidism. I am indebted to these colleagues for permission to quote the data, and to Dr. Nora Blackwell, of this Unit, who analysed the cells from the iodine-treated patients. Clearly, in a short contribution to a symposium, it is impossible to present data in full, or to discuss them alone or in association with the literature.

There is no need to consider the findings in the first series of ${ }^{198} \mathrm{Au}$ and ${ }^{90} \mathrm{Y}$ patients, as the data have been presented in full in the Annals of the Rheumatic Diseases. However, the use by rheumatologists of colloidal suspensions of particulate ${ }^{198} \mathrm{Au}$ and ${ }^{90} \mathrm{Y}$ presented a unique opportunity to study one aspect of chromosomal damage from radio-isotopesnamely, the effects of distribution in the body on the types of tissue absorbing released energy and the 
relationship of dosage to chromosome aberration yield.

You will remember that, in essence, the findings in lymphocytes of patients who have had intra-articular injections of ${ }^{198} \mathrm{Au}$ and ${ }^{90} \mathrm{Y}$ in colloidal suspension showed:

(a) That there was evidence in almost all patients of a significant amount of chromosome damage in lymphocytes of a type which, with the techniques employed, indicated that this damage had occurred in vivo (The rationales of the techniques employed, and the reasoning as to the genesis of the chromosomal damage are considered in UNSCEAR (1969) and Stevenson, Bedford, Hill, and Hill (1971a)).

(b) That the amount of chromosome damage in the lymphocytes was much greater than would have been expected if either isotope had been uniformly distributed in the body.

(c) That, per unit of activity injected, there were very large differences in the amount of damage found in patients, so that correlations of frequency of damage and amounts of activity ingested were low and not significant, even if corrections were made for the half life of the lymphocytes based on the intervals between treatment and test.

(d) That, although the number of patients who had been scanned for distributions of the isotopes was small, there were strong indications, particularly for ${ }^{198} \mathrm{Au}$, that the amount of chromosome damage in lymphocytes was related to the amount of activity which left the injected joints, and to the integral dose to the related lymph nodes expressed in $\mathrm{mCi}$. per day.

(e) That, from the distribution of amounts of damage in individual cells, using dicentric chromosomes as an indicator, the dosage to different lymphocytes had varied greatly.

It was concluded that most phenomena observed were explicable on the basis that the dosage to lymphocytes, even from ${ }^{198} \mathrm{Au}$, which is also a $\gamma$ - emitter, was predominantly from the short range $\beta$ particles in the lymph nodes receiving the drainage from the joints. The patterns of damage and their significance in understanding the circulation of lymphocytes will be discussed by Dr. Dolphin.

The findings in these two studies are summarized in the Table (rows $\mathbf{A}$ and $\mathbf{B}$ ), which also gives the data for the other three studies mentioned above. In the first two studies the data from follow-up of patients 1 month after injection only are included (two patients having ${ }^{198} \mathrm{Au}$ and seven having ${ }^{90} \mathrm{Y}$ ).

Rows C, D, and E in the Table set out parallel findings in the further ten patients of Dr. Andrews who had had intra-articular ${ }^{90} \mathrm{Y}$, twelve patients of Prof. Kinmonth who had had endolymphatic ${ }^{32} \mathrm{P}$ labelled lipiodol, and the 28 patients of Dr. Wiernik who had had oral ${ }^{131}$ I.

It must be emphasized that a number of assumptions, many of which are difficult to justify, had to be made in order to produce such a summary Table, suitable for presentation in a symposium, so that some of the comparisons which I wish to make are open to criticism. Certainly, it is probably hazardous to use formal tests of significance in these comparisons.

Papers are in preparation concerning the lipiodol and iodine studies, and in these the data will be presented in full and the literature considered. I propose to concentrate on the parameter of frequency of dicentric chromosomes as the indicator of chromosomal damage because this is the one increasingly accepted as the most valid, although the sum dicentric and centric ring chromosome frequencies are used by some authors. The advantages of either parameter are that these types of chromosome damage are characteristic of radiation damage, and are so uncommon in control subjects (less than 1/2,000 and $1 / 5,000$ respectively), that any found can be attributed to irradiation, with certain reservations

Table Summary of chromosome findings in lymphocytes of five series of patients treated with radio-isotopes All findings are in PHA-stimulated cultures harvested after 48 hours

\begin{tabular}{|c|c|c|c|c|c|c|c|c|c|c|c|c|c|c|c|c|}
\hline Series & $\begin{array}{l}\text { Isotope and mode of } \\
\text { administration }\end{array}$ & $\begin{array}{l}\text { No. of } \\
\text { patients }\end{array}$ & $\begin{array}{l}\text { Mean } \\
\text { dose } \\
(m C i .)\end{array}$ & $\begin{array}{l}\text { Total } \\
\text { cells } \\
\text { analysed }\end{array}$ & $\begin{array}{l}\text { Mean } \\
\text { damaged } \\
\text { cells per } \\
\text { mCi. } \\
\text { per cent. }\end{array}$ & $\begin{array}{l}\text { Mean no. of dicentric } \\
\text { chromosomes } \\
\text { per mCi. } \\
\text { per IOO cells } \\
\text { ('corrected')" }\end{array}$ & $\begin{array}{l}\text { Mean no. of ring } \\
\text { chromosomes } \\
\text { per mCi. } \\
\text { per } 100 \text { cells } \\
\text { ('corrected')" }\end{array}$ & \multicolumn{9}{|c|}{$\begin{array}{l}\text { Distribution of dicentric } \\
\text { chromosomes } \\
\text { Cells with numbers of dicentrics } \\
\text { (not 'corrected') }\end{array}$} \\
\hline $\mathbf{A}$ & ${ }^{198} \mathrm{Au}$ intra-articular & 48 & $15 \cdot 6$ & 15791 & $0 \cdot 30$ & 0.46 & 0.04 & 15369 & 318 & 65 & 20 & 11 & 1 & 6 & 1 & 0 \\
\hline B & ${ }^{90} \mathrm{Y}$ intra-articular & 22 & $5 \cdot 8$ & 7058 & 0.56 & 0.52 & 0.04 & 6931 & 104 & 12 & 5 & 4 & 1 & 0 & 1 & $\mathbf{0}$ \\
\hline $\mathbf{D}$ & $\begin{array}{l}\text { Lipiodol 32P } \\
\text { endolymphatic }\end{array}$ & 12 & $6 \cdot 1$ & 1900 & 0.63 & 0.67 & 0.06 & 1856 & 41 & 2 & 0 & 0 & 0 & 0 & $\mathbf{0}$ & 1 \\
\hline $\mathbf{E}$ & 131 I oral & 28 & $9 \cdot 5$ & 4300 & $0 \cdot 14$ & 0.23 & 0.01 & 4066 & 27 & 4 & 3 & 0 & 0 & 0 & 0 & $\mathbf{0}$ \\
\hline
\end{tabular}

* 'corrected' figures are the result of multiplying the observed frequencies per 100 cells per mCi. by a factor based on the assumption of a mean three year half life of cells carrying dicentric or centric ring chromosomes.

$A$ and $B-S t e v e n s o n$ and others (1973).

C-Cases treated by Dr. F. M. Andrews, The Battle Hospital, Reading.

D-Cases treated in the department of Prof. J. B. Kinmonth, St Thomas' Hospital, London.

E-Cases treated by Dr. G. Wiernik, Churchill Hospital, Oxford, analysed by Dr. Nora Blackwell. 
concerning effects of some drugs. The other types of damage (as considered in UNSCEAR, 1969) could have occurred among earlier cell generations in vivo, or are indistinguishable from the results of isochromatid breaks arising in culture. The latter occur in a mean frequency approaching 1 per cent. in normal cultures, with a fairly high sampling range. It will be seen that there is no great difference in mean corrected dicentric frequency per $\mathrm{mCi}$. between the original gold and yttrium data, but that the level is lower in Dr. Andrews' patients. However, the difference is only just significant if corrections are made for intervals from treatment to test. The mean interval in Dr. Andrews' patients was considerably higher than in the preceding series.

I understand from Dr. Andrews that his patients were all rested for 48 hours after injection. In the first series, post-injection treatment was very variable, and many were treated as outpatients. Subsequent to our first publication, de la Chapelle, Oka, Rekonen, and Ruotsi (1972) have reported the findings in eleven patients given intra-articular injections of ${ }^{90} \mathrm{Y}$ whose limbs were not immobilized and fourteen patients whose limbs were immobilized after treatment. Scanning of these patients showed that the radiation dose to the lymph nodes was reduced by nearly 80 per cent. by immobilization. However, the mean yield of dicentrics + centric rings per $\mathrm{mCi}$. per 100 cells was surprisingly similar and, indeed, higher in immobilized $(0 \cdot 15)$ than in non-immobilized $(0 \cdot 11)$ patients. This finding is compatible with the finding of the authors that their estimated lymph node dosage did not correlate with the frequency of dicentrics plus rings.

It is clear that the findings in these studies raise many points for discussion. I understand that, in a number of centres in this country, limbs are now being immobilized for a day or two after injections. I do not know whether scanning studies have been carried out. Perhaps we shall hear today. Certainly, I think further chromosome studies in treated patients should be undertaken, because the results from Finland, assuming the estimated node doses are correct, are difficult to reconcile with the hypothesis advanced by Stevenson and others (1973).

The findings in the patients treated for malignant melanoma by endolymphatic injections of ${ }^{32} \mathrm{P}$ labelled lipiodol are of interest, in that studies of chromosomes of such patients have not previously been reported, and in that they can be compared with the ${ }^{198} \mathrm{Au}$ and ${ }^{90} \mathrm{Y}$ treated patients. It might be expected that a very high proportion of the ${ }^{32} \mathrm{P}$ labelled lipiodol injected into lymphatic vessels would reach the lymph nodes draining the area (three were into the upper and the remaining nine into the lower limb). The amount of damage per $\mathrm{mCi}$. injected would consequently be expected to be relatively high. As may be seen from the Table, the mean level of dicentrics per millicurie per 100 cells is higher than in the patients in the other studies. ${ }^{32} \mathrm{P}$ of course is only a $\beta$ emitter. The half life is $\mathbf{1 4 \cdot 2}$ days (compared with the shorter half lives of $2 \cdot 7$ days for ${ }^{198} \mathrm{Au}$ and ${ }^{90} \mathrm{Y}$ ), and the $\beta$-particle energy (all $1.71 \mathrm{MeV}$.) is intermediate between the mean energies of ${ }^{198} \mathrm{Au}$ and ${ }^{90} \mathrm{Y}$ particles. Unfortunately, data which have been assembled on the distribution and excretion of the radioactive lipiodol have not yet been related to the amount of chromosome damage. Indeed, more concentrated studies would be necessary to define the situation more accurately.

I shall leave the discussion of the very difficult subject of lymphocyte dosimetry to others, but it does seem clear that some of the lipiodol injected into a lymphatic vessel reaches the draining nodes in a few minutes, some remains in the nodes for a long period ( 6 to 8 weeks) even if the node is not damaged (Desprez-Curely, Bismuth, Laugier, and Descamps, 1962; Richardson, Crosby, Bean, and Dexter, 1966), and some passes through the nodes. Some of the iodinized oil is broken down and the unchanged remnant becomes broken up into smaller and smaller droplets. Some of these droplets reach the lungs 15 to 20 minutes after injection and some of them are sufficiently small to pass through the pulmonary capillaries. According to Elke (1965), at 3 days the content in the lungs is about 50 per cent. of the amount injected into lymph vessels. Koehler, Meyers, Skelley, and Schaffer (1964) found that by 6 days only 13 per cent. had been excreted in the urine and elimination from the kidney was much slower thereafter. Clearly, only a careful combination of radiography and activity scanning would yield data which could be related realistically to chromosome damage observed in treated patients. It is obviously unlikely that there is uniform irradiation of body tissues, and that lymph node dosage would be expected to be relatively high, and that lung and kidney dosage would be higher than in other tissues.

The data from the 28 patients who had had oral ${ }^{131} \mathrm{I}$ are shown in the Table, row E. Three further patients investigated have been excluded because search showed that they had had radiotherapy. It will be seen that the corrected frequency of dicentric chromosomes per 1,000 cells per $\mathrm{mCi}$. is lower than in $\mathrm{A}, \mathrm{B}$, or $\mathrm{D}$, and a little higher but not dissimilar to those for the Reading series of ${ }^{90} \mathrm{Y}$ treated patients. However, the 'correction' for interval from treatment to test is rather unrealistic, as for several patients the factor was three or more, multiplying alarmingly any sampling variation. Dr. Dolphin has made careful estimates of the lymphocyte dosimetry from ${ }^{131} I$ patients and has attempted to relate them to estimates based on the amount of chromosome damage. On the basis of his physical estimates, he calculated that the mean whole body dose per $\mathrm{mCi}$. of ${ }^{131} \mathrm{I}$ ingested would be about $0.6 \mathrm{r}$, so that the mean dose in the patients 
reported in the Table would be about $6 \mathrm{r}$. However, the frequency of dicentrics per cell (not 'corrected') in these patients was $44 / 4,300$ (or 1 per cent.), which is much more than would be expected from an external whole body dose of such size.

Looking at the data as a non-physicist, and bearing in mind that not all the iodine would be absorbed from the gut, that the half life is just over 8 days, and the half life in the thyroid is shorter, and that much of the released energy is $\gamma$, it is perhaps surprising that the level of damage is so high.

Looking at the Table as a whole, there are a number of points of interest. First, it has to be realized that over 30,000 cells were analysed in the various studies. This is an enormous number, yet, particularly in B, C, and D, the standard errors of the proportions are high. Further to reduce sampling errors to a significant extent, the amount of work involved would be enormous.

In consideration of the first ${ }^{198} \mathrm{Au}$ and ${ }^{90} \mathrm{Y}$ work, it was pointed out that the departure from expectation on a Poisson hypothesis of the distribution of dicentrics in cells was compatible with an explanation of most of the lymphocyte exposure being on lymph nodes, and that the dosage to them varied from zero to very high.

That it was possible with some confidence to recognize the non-Poisson distribution from the data was due to two factors: the relatively high frequency of dicentrics, and the very large numbers of lymphocytes analysed. Neither of these apply to B, C, or D, or to the data of de la Chapelle and others (1972). It seems important to extend studies of the effects of endolymphatic lipiodol ${ }^{32} \mathrm{P}$, and of ${ }^{131} \mathrm{I}$, because the data suggest non-Poisson distributions.

I shall not attempt to discuss the prognostic implications of chromosome damage induced in these ways. They were discussed both at the meeting at Stoke Mandeville in January, 1972, and by Stevenson and others (1973), and there appears to be nothing to add to these inconclusive arguments.

Finally, as there are many rheumatologists here, may I ask that any who have not received the request for data to enable treated patients to be followed up will get in touch with me; and also will those who have promised to co-operate but have not yet sent completed proformas please do so as soon as possible. 